\title{
Simple clinical method of measuring gastric emptying of solid meals
}

\author{
D. G. OSTICK ${ }^{1}$, G. GREEN, K. HOWE, I. W. DYMOCK ${ }^{2}$, AND D. J. COWLEY 3 \\ From the Departments of Surgery and Medicine, University Hospital of South Manchester, and the \\ Department of Medical Biophysics, University of Manchester, Manchester
}

SUMMARY The radioisotope techniques used for the measurement of gastric emptying of solid meals in man require complex and expensive scintiscanners or gamma cameras. We have evaluated a simple technique which uses a fixed scintillation detector and compared the results with those obtained from a gamma camera. The rates and patterns of gastric emptying recorded by the two methods correlated well in both healthy volunteers (mean $r=0.95$ ) and patients with duodenal ulcer (mean $r=0 \cdot 89$ ). The scintillation detector provides a reliable and inexpensive method for measurement of gastric emptying of solid meals.

Radioisotope labelling of foods has allowed the rate of gastric emptying of solid meals to be recorded using external counters such as a scintillation scanner (Griffith et al., 1966) or a gamma camera (Jones et al., 1970). The equipment is expensive and the methods have had little clinical application. In the present study, a simpler method which uses a single fixed scintillation detector has been evaluated. The results in both healthy volunteers and patients with duodenal ulcer have been compared with those obtained simultaneously by a gamma camera.

\section{Methods}

Twenty healthy volunteers and 10 patients with duodenal ulcer were studied (two before and eight after operation). Each subject ate a meal consisting of a standard portion of porridge (Ready Brek), a slice of buttered bread with marmalade, and a glass of milk. Volume of the meal was $400 \mathrm{ml}$ and the caloric value $650 \mathrm{Cal}$. The porridge was labelled with 500 $\mu \mathrm{Ci}{ }^{99 \mathrm{~m}}$ Technetium sulphur colloid before preparation. Studies in vitro had shown that $99 \mathrm{~m}$ Tc sulphur colloid was bound to the solid component of this meal even when mixed with fresh gastric juice (Ostick, unpublished data).

Radioactivity from the gastric area was counted simultaneously with (1) a gamma camera with on-

\footnotetext{
${ }^{1}$ Address for reprint requests: Mr D. G. Ostick, Department of Surgery, University Hospital of South Manchester, West Didsbury, Manchester M20 8LR.

'Present address: Stepping Hill Hospital, Stockport, Cheshire. 'Present address: Victoria Hospital, Blackpool, Lancashire.

Received for publication 21 January 1976
}

line computer (Med II system Nuclear Data), using a method similar to that described by Hancock $e t$ al. (1974); (2) a single scintillation detector (EP151) connected to a counter ratemeter (MS 310, J. \& P. Engineering). The scintillation detector was arranged as shown in Fig. 1. The counter ratemeter was set over the photopeak for ${ }^{99 \mathrm{~m}} \mathrm{Tc}$ and the channel width at $20 \%$. All healthy volunteers were studied in the erect position; some of the duodenal ulcer patients were erect and some supine.

After the subject had eaten the meal, the gamma camera was positioned over his stomach with the aid

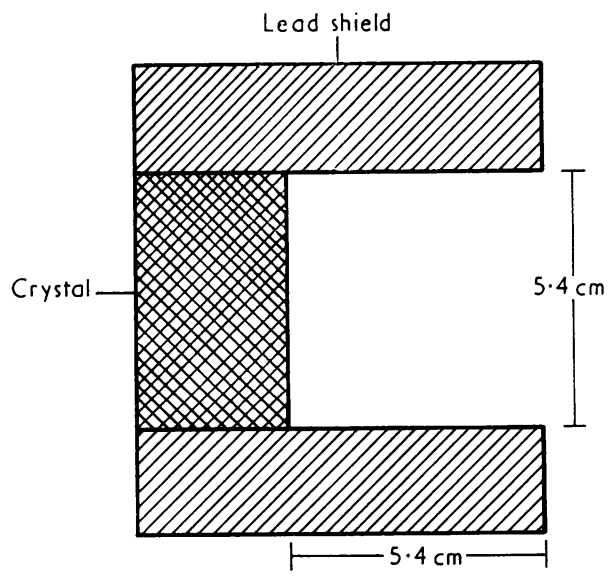

Fig. 1 Position of the sodium iodide crystal in the scintillation detector. 
of an oscilloscope display. The scintillation detector was positioned against the subject's left side and carefully fixed over the area of maximal activity. Counts were taken for $2 \frac{1}{2}$ minutes every seven minutes with the gamma camera and for 10 seconds at the end of every seven minutes with the scintillation detector. In some studies, scintillation detector counts were made for both $\mathbf{1 0}$ seconds and $\mathbf{4 0}$ seconds for comparison.

Activity from the gamma camera was stored on a magnetic disc in the computer and, at the end of recording, the gastric area was delineated on a television display with a light pen. The computer, which had been programmed, counted the radioactivity in this area and subtracted background contribution. Scintillation detector results appeared as simple numbers on the counter ratemeter and, for both methods, the results were expressed as a percentage of the initial count. Half emptying times ( $\left.T \frac{1}{2}\right)$ were calculated by the method of least squares from the regression line of the logarithm of count rate against time on a linear scale. All time measurements were related to the start of the recording not the start of the meal and no estimation was made of the gastric emptying which might have occurred in this period. The time between starting the meal and the start of recording ranged from nine to $14 \frac{1}{2}$ minutes (mean 12 minutes).

\section{Results}

For the 20 volunteers, the mean radioactivity remaining in the stomach at each count was calculated (Table). The mean results were compared using Student's $t$ test for paired data and the standard deviations were compared using Snedecor's F values. There was no significant difference between the gamma camera and scintillation detector results with either statistical method ( $>0 \cdot 1)$. The mean emptying patterns obtained simultaneously by the gamma camera and the scintillation detector correlated closely (Fig. 2). Coefficients of correlation were

\begin{tabular}{|c|c|c|}
\hline Count & Gamma camera & Scintillation detector \\
\hline 1 & $100 \pm 0$ & $100 \pm 0$ \\
\hline 2 & $89.1 \pm 6.5$ & $90 \cdot 4 \pm 10.3$ \\
\hline 3 & $80.1 \pm 8.0$ & $81.3 \pm 11.6$ \\
\hline 4 & $71.8 \pm 9.5$ & $71.9 \pm 11.6$ \\
\hline 5 & $64.8 \pm 0.2$ & $65.6 \pm 13.9$ \\
\hline 6 & $59.8 \pm 11.2$ & $59.6 \pm 15.7$ \\
\hline 7 & $53 \cdot 3 \pm 12 \cdot 0$ & $54 \cdot 8 \pm 14 \cdot 1$ \\
\hline 8 & $47 \cdot 2 \pm 12 \cdot 4$ & $48 \cdot 7 \pm 13 \cdot 1$ \\
\hline 9 & $44 \cdot 3 \pm 11 \cdot 9$ & $43.2 \pm 11 \cdot 1$ \\
\hline 10 & $39 \cdot 2 \pm 12 \cdot 5$ & $37.0 \pm 9.2$ \\
\hline
\end{tabular}

Table Radioactivity (as percentage of initial activity) which remained in stomach at each time interval of seven minutes using two methods

Mean of 20 volunteers \pm SD.

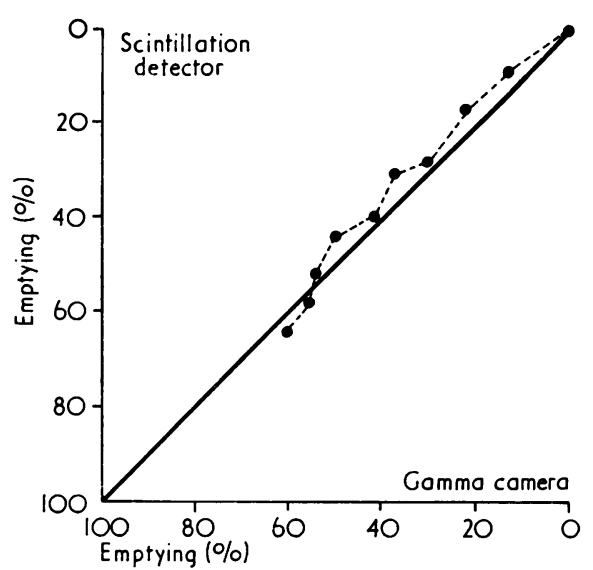

Fig. 2 Mean gastric emptying of the 20 volunteers relating the gamma camera and scintillation detector methods.

calculated for individual subjects and ranged from $r=0.76$ to $r=0.99$ (mean $r=0.95$ ) for the 20 volunteers and from $r=0.65$ to $r=0.98$ (mean $r=$ $0 \cdot 89$ ) for the duodenal ulcer patients.

The mean half emptying time (T⿺辶) volunteers was 49.3 minutes (S.D. $\pm 19 \cdot 9$ ) with the gamma camera and $48 \cdot 2$ minutes (S.D. $\pm 21 \cdot 1$ ) with the scintillation detector. Results correlated well from the two methods in both volunteers and patients (Figs 3 and 4).

In six of the studies, scintillation detector counts were made for 10 seconds and 40 seconds in each seven minute period, there was no difference in the percentage decrease in activity in each seven minute period.

\section{Discussion}

Measurement of the rate of gastric emptying of labelled food requires complex external counters and the clinical possibilities must be limited by the intricacy and expense of this equipment (Sheiner, 1975). The scintillation detector and counter ratemeter are inexpensive, the method is simple, and the results easily calculated. When the results were compared with those obtained simultaneously from a sophisticated and very expensive gamma camera method (Hancock et al., 1974), a good correlation was demonstrated in healthy volunteers and patients with duodenal ulcer.

The scintillation detector was positioned on the subject's left side and accurately manoeuvred over the area of maximal activity. In a small pilot study the detector was placed on the subject's right side, 


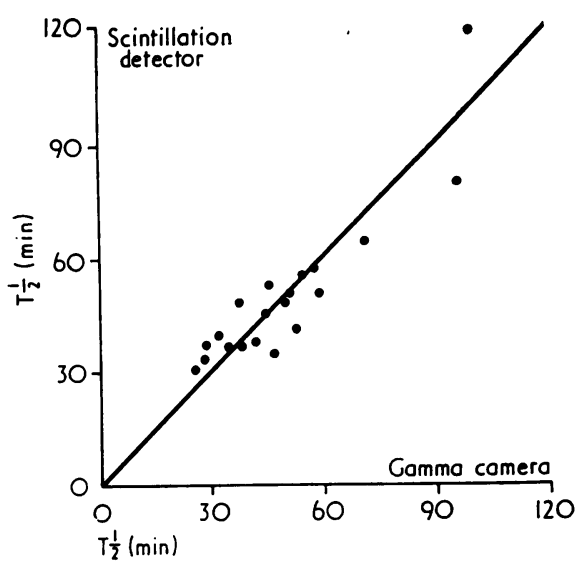

Fig. 3 Half emptying times ( $\left.T \frac{1}{2}\right)$ of the 20 volunteers relating the gamma camera and scintillation detector results.

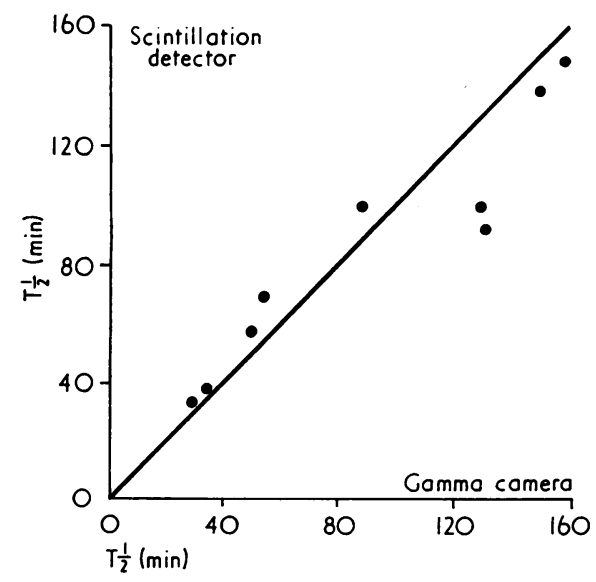

Fig. 4 Half emptying times ( $\left.T \frac{1}{2}\right)$ of nine $D U$ patients relating to results from the two methods. One patient with grossly delayed emptying not included.

but the results did not correlate with those from the gamma camera. This could be explained by the anatomical position of the stomach, so that at this greater distance from the stomach the detector would count activity from the small bowel. The results were valid only if the detector was accurately positioned over the area of maximal activity, the rate of decrease of activity from this area being proportional to the rate at which labelled food left the stomach. This is confirmed by the close correlation with the gamma camera results. Analysis of the gamma camera records suggested that the area of maximal activity was in the body of the stomach. The position of the stomach is assumed to remain constant in both methods, this assumption is supported by review of our gamma camera records.

In this study, the solid component of the meal was labelled with ${ }^{99 \mathrm{~m}} \mathrm{Tc}$ sulphur colloid and the rate of emptying of this component was measured. It is possible that the liquid component of the meal emptied at a different rate and therefore important to know the distribution of the isotope in the chosen meal. 99m Technetium emits a high proportion of gamma radiation and has a short half life (six hours); high external counts were recorded in periods of 10 seconds with the scintillation detector and the high gamma emission assisted the initial positioning of the detector.

Using external counters to measure gastric emptying has certain drawbacks (Alexander-Williams et al., 1973). The main drawback was that emptying may have started while the meal was being eaten and no allowance could be made for this, using the scintillation detector. Also, radioactivity which had entered the small bowel could be counted, but the scintillation detector was probably positioned over the body of the stomach so that overlap by the small bowel was unlikely.

The scintillation detector is reliable and inexpensive; this simple non-invasive method could be used to measure gastric emptying of solid meals in further research studies and in the assessment of patients with suspected disorders of gastric emptying.

We would like to thank Professor B. Pullan for providing the facilities used in this study, Professor B. Pullan and Professor R. A. Sellwood for their encouragement, and Mrs E. M. McCreery and Miss C. Keenan for their secretarial help.

\section{References}

Alexander-Williams, J., Donovan, I. A., Gunn, I. F., Brown, Ann, and Harding, L. K. (1973). The effect of vagotomy on gastric emptying. Proceedings of the Royal Society of Medicine, 66, 1102-1103.

Griffith, G. H., Owen, G. M., Kirkman, S., and Shields, R. (1966). Measurement of rate of gastric emptying using Chromium-51. Lancet, 1, 1244-1245.

Hancock, B. D., Bowen-Jones, E., Dixon, R., Dymock, I. W., and Cowley, D. J. (1974). The effect of metaclopramide on gastric emptying of solid meals. Gut, 15, 462-467.

Jones, T., Clark, J. C., Kocak, N., Cox, A. G., and Glass, H. I. (1970). Measurement of gastric emptying using the scintillation camera and ${ }^{129}$ Cs. British Journal of Radiology, 43, 537-541.

Sheiner, H. J. (1975). Gastric emptying tests in man. Gut, 16, 235-247. 